University of Wollongong

Research Online

Faculty of Engineering - Papers (Archive)

Faculty of Engineering and Information

Sciences

2008

\title{
An improved methodology for determining MV to LV voltage unbalance transfer coefficient
}

Prabodha Paranavithana

University of Wollongong, ptp123@uow.edu.au

Sarath Perera

University of Wollongong, sarath@uow.edu.au

Robert Koch

Eskom Holding Limited

Follow this and additional works at: https://ro.uow.edu.au/engpapers

Part of the Engineering Commons

https://ro.uow.edu.au/engpapers/5400

\section{Recommended Citation}

Paranavithana, Prabodha; Perera, Sarath; and Koch, Robert: An improved methodology for determining MV to LV voltage unbalance transfer coefficient 2008.

https://ro.uow.edu.au/engpapers/5400

Research Online is the open access institutional repository for the University of Wollongong. For further information contact the UOW Library: research-pubs@uow.edu.au 


\title{
An Improved Methodology for Determining MV to LV Voltage Unbalance Transfer Coefficient
}

\author{
Prabodha Paranavithana, Student Member, IEEE, Sarath Perera, Member, IEEE, and Robert Koch
}

\begin{abstract}
The International Electrotechnical Commission (IEC) has recently released a technical report (IEC/TR 610003-13, Ed. 1.0, 2008) in relation to the assessment of voltage unbalance emission by installations connected to MV, HV and EHV power systems. As in the cases of harmonics and flicker, this requires a quantitative measure of propagation of voltage unbalance from upstream (higher voltage) to downstream (lower voltage) systems in terms of transfer coefficients. Naturally, these transfer coefficients depend on the downstream load composition. The existing method for determining MV to $L V$ voltage unbalance transfer coefficient suggests a value of unity in relation to passive loads in general. However, this paper reports that MV to $\mathrm{LV}$ transfer coefficient of unity is conservative in the presence of commonly prevailing constant power loads. Further, the paper reports on an improved methodology for estimating MV to $\mathrm{LV}$ voltage unbalance transfer coefficient taking system and load characteristics into account.
\end{abstract}

Index Terms-voltage unbalance, transfer coefficients, MV and LV power systems, passive loads, three-phase induction motors

\section{INTRODUCTION}

C IGRE/CIRED Joint Working Group C4.103 has been active in developing guidelines for determining the negative sequence voltage unbalance emission limits to unbalanced three-phase installations connected at different voltage levels of power systems [1] - [3]. As a result, a new IEC technical report (IEC/TR 61000-3-13, Ed. 1.0, 2008 [4]) has been recently released which enables system operators to coordinate voltage unbalance between various voltage levels in order to ensure adequate quality of supply at the points of utilisation across the entire system.

The philosophy of the principles used in IEC/TR 610003-13 is similar to the IEC recommendations for harmonics (IEC 61000-3-6 [5]) and flicker (IEC 61000-3-7 [6]). The compatibility levels are used as reference values for coordinating the emission and the immunity of equipment or installations which are part of, or supplied by, a power system in order to ensure the electromagnetic compatibility in the whole system. Coordination of voltage unbalance at different voltage levels is achieved by means of the planning levels (set as internal quality objectives) such that the compatibility levels are not exceeded. The general principle used to ensure coordination of the disturbance is such that the total emission level derived using the general summation law, taking transfer coefficients between deferent parts into account, at any point of the system,

Prabodha Paranavithana and Sarath Perera are with the School of Electrical, Computer and Telecommunications Engineering, University of Wollongong, and are Members of the Integral Energy Power Quality and Reliability Centre, NSW 2522, Australia (email: ptp123@uow.edu.au).

Robert Koch is with Eskom Holdings Limited, Resources and Strategy Division, Eskom Research and Innovation Centre, Private Bag 40175, Cleveland, 2022, South Africa. should not exceed the set planning level. Based on the above principle the system absorption capacity or the maximum global contribution to the disturbance is established as:

$$
U_{\text {global }}^{i}=\sqrt[\alpha]{\left(L^{i}\right)^{\alpha}-\left(T_{u s-i} L^{u s}\right)^{\alpha}}
$$

where,

$i$ - represents the downstream system in which the emission level has to be assessed

us - represents the upstream (US) system from which the voltage unbalance propagates to the downstream system $i$

$L^{i}, L^{u s}$ - planning levels of system $i$ and US system respectively

$\alpha$ - summation law exponent

$T_{u s-i}$ - transfer coefficient from US system to system $i$

$U_{\text {global }}^{i}$ - allowed global contribution (ie. from system $i$ and the downstream) to voltage unbalance

The maximum global contribution $U_{g l o b a l}^{i}$ is then apportioned to individual customers according to their agreed apparent power with respect to the total available power of the system reflected at the point of evaluation taking into account the global emission caused by system inherent asymmetries (using a factor referred as ' $K u e$ ' [1] - [4]).

The voltage unbalance transfer coefficient defined by (2) represents the fraction of US voltage unbalance transferred to the considered downstream system $i$ :

$$
T_{u s-i}=\frac{U^{i}}{U^{u s}}
$$

where,

$U^{u s}, U^{i}$ - voltage unbalance (in terms of VUF - voltage unbalance factor) in US system and system $i$ respectively

Equation (1) requires estimation of the voltage unbalance transfer coefficient so that the headroom available for connecting unbalanced installations can be determined. Underestimation of the transfer coefficient may result in emission above the planning level, whereas overestimation causes unnecessary limitation on individual customers.

Reference [2] gives an approximation to the MV (upstream) to LV (downstream) transfer coefficient $\left(T_{m v-l v}\right)$ as:

$$
T_{m v-l v} \approx \frac{1}{1+k_{m}\left(\frac{k_{s}-1}{k_{s c}+1}\right)}
$$

where,

$k_{m}$ - ratio between the rated motor load (in MVA) and the total load (in MVA) supplied by the LV system

$k_{s}$ - ratio between the positive and negative sequence impedances of the motor load supplied by the LV system 
$k_{s c}$ - ratio between the LV short circuit level (in MVA) and the total load (in MVA) supplied by the LV system

Equation (3) suggests that a value less than unity can be expected for $T_{m v-l v}$ when the LV system supplies an industrial load base containing a large proportion of threephase induction motors, whereas a unity $T_{m v-l v}$ can be used in relation to passive loads. Although $T_{m v-l v}=1$ seems obvious in relation to constant impedance loads, constant current and constant power loads may lead to different results owing primarily to different behaviour exhibited by such loads under unbalanced supply conditions. As an example, Fig. 1 illustrates the variation of $T_{m v-l v}$ with $k_{s c}$ (representing various system characteristics) established using three-phase load flow analysis [7] when the LV system supplies a load base primarily having constant power elements with 0.9 lagging power factor, compared against unity. This suggests that $T_{m v-l v}=1$ cannot be used confidently in the presence of all types of passive loads.

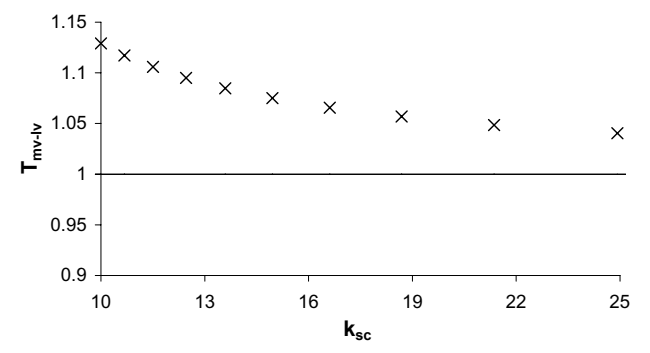

Fig. 1. Variation of $T_{m v-l v}$ with $k_{s c}$ in relation to a load base containing constant power elements with 0.9 lagging power factor

The objective of the work presented in this paper is to examine the influence of behaviour of various load types on the voltage unbalance propagation in detail taking various system characteristics into account so that a generalised and improved methodology for determining $T_{m v-l v}$ can be established.

The paper is organised as follows: Section II establishes the required background for deriving the transfer coefficient $T_{m v-l v}$ in relation to various load bases. The behaviour of constant impedance, constant current, constant power and threephase induction motor loads are addressed in Sections III, IV, $\mathrm{V}$ and VI respectively. A generalised expression for $T_{m v-l v}$ is established incorporating the impact of various load types in Section VII. Conclusions are given in Section VIII.

\section{BACKGROUND FOR DERIVATION OF $T_{m v-l v}$}

Consider the MV-LV radial system shown in Fig. 2 where the MV busbar (upstream) is considered as a slack busbar but unbalanced. For the purpose of assessing the voltage unbalance transferred from upstream MV system to downstream LV system the loads supplied by the LV busbar are taken as balanced. The transfer coefficient $T_{m v-l v}$ which is defined as the ratio between VUFs at LV and MV busbars can be expressed as:

$$
T_{m v-l v}=\left|\frac{V_{-}^{l v}}{V_{+}^{l v}}\right| \times \frac{1}{\left|\frac{V_{-}^{m v}}{V_{+}^{m v}}\right|}=\left|\frac{V_{-}^{l v}}{V_{-}^{m v}}\right| \times \frac{1}{\left|\frac{V_{+}^{l v}}{V_{+}^{m v}}\right|}
$$

where,

$V_{+}^{l v}, V_{+}^{m v}$ - positive sequence voltages at the LV (referred to primary side of the MV-LV transformer) and MV busbars respectively

$V_{-}^{l v}$ - negative sequence voltage at the LV busbar (referred to primary side of the MV-LV transformer) transferred from the MV system

$V_{-}^{m v}$ - negative sequence voltage prevailing at the MV busbar

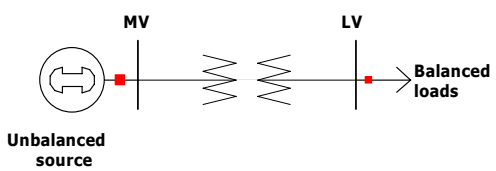

Fig. 2. MV-LV radial system

The ratio $\left|\frac{V_{+}^{l v}}{V_{+}^{m v}}\right|$ in (4) can be generally expressed as:

$$
\left|\frac{V_{+}^{l v}}{V_{+}^{m v}}\right| \approx \frac{1}{|1+j| \frac{Z_{++: t f}^{\prime}}{Z_{++: \text {load }}}\left|\angle \theta_{p f}\right|}
$$

where,

$Z_{++: t f}^{\prime}$ - positive sequence impedance (assumed as inductive) of the MV-LV transformer referred to secondary

$Z_{++: \text {load }}$ - equivalent positive sequence impedance of the total load supplied by the LV busbar

$\theta_{p f}-$ power factor angle ( - and + for lagging and leading conditions respectively) of the total load supplied by the LV busbar

The impedances $Z_{++: t f}^{\prime}$ and $Z_{++: \text {load }}$ are approximately and inversely proportional to the short circuit capacity (in MVA) at the LV busbar and to the total load (in MVA) supplied by the LV busbar respectively. Hence, the ratio $\left|\frac{Z_{++: t f}^{\prime}}{Z_{++ \text {:load }}}\right|$ in (5) can be expressed as:

$$
\left|\frac{Z_{++: t f}^{\prime}}{Z_{++ \text {load }}}\right| \approx \frac{1}{k_{s c}}
$$

Then, (5) can be rearranged substituting (6) as:

$$
\left|\frac{V_{+}^{l v}}{V_{+}^{m v}}\right| \approx \frac{1}{\left|1+j \frac{1}{k_{s c}} \angle \theta_{p f}\right|}
$$

The negative sequence voltage at the LV busbar arising as a result of the unbalanced voltages at the MV busbar can be generally written as:

$$
\left|V_{-}^{l v}\right|=\left|V_{-}^{m v}-Z_{++: t f} I_{-: t f}\right|
$$

where,

$Z_{++: t f}$ - positive sequence impedance of the MV-LV transformer referred to primary

$I_{-: t f}$ - negative sequence current in the transformer primary caused by the MV unbalance

The behaviour of the negative sequence current $I_{-: t f}$ in (8) seems to depend on the type of loads supplied by the system, making the resultant negative sequence voltage 
$\left|V_{-}^{l v}\right|$ dependant on the load type. This will be addressed in Sections III - VI in relation to the four basic load types (ie. constant impedance, constant current and constant power loads and three-phase induction motors).

\section{CONSTANT IMPEDANCE LOADS}

When the LV busbar supplies constant impedance loads (balanced: equal positive and negative sequence impedances), (8) can be simplified as:

$$
\left|V_{-}^{l v}\right|=\frac{\left|V_{-}^{m v}\right|}{\left|1+\frac{Z_{++: t f}^{\prime}}{Z_{++ \text {load }}}\right|} \approx \frac{\left|V_{-}^{m v}\right|}{\left|1+j \frac{1}{k_{s c}} \angle \theta_{p f}\right|}
$$

Substituting (7) and (9) in (4):

$$
T_{m v-l v}=1
$$

\section{Constant CurRent Loads}

The negative sequence current $I_{-: t f}$ in (8) can be considered to be negligible when the system supplies constant current loads (balanced), as such loads draw equal magnitudes of three-phase currents regardless of the prevailing voltage condition. Hence, (8) can be simplified in relation to constant current loads as:

$$
\left|V_{-}^{l v}\right| \approx\left|V_{-}^{m v}\right|
$$

Substituting (7) and (11) in (4):

$$
T_{m v-l v} \approx\left|1+j \frac{1}{k_{s c}} \angle \theta_{p f}\right|
$$

That is, the transfer coefficient $T_{m v-l v}$ increases by the factor $\left|1+j \frac{1}{k_{s c}} \angle \theta_{p f}\right|$ relative to the conservative value of unity when the system supplies constant current loads. Figs. 3 and 4 illustrate the variation of $T_{m v-l v}$ with $k_{s c}$ in relation to constant current loads with 0.99 and 0.9 power factor (lagging) respectively. A range for $k_{s c}$ between 10 (eg. fully loaded 10MVA transformer with $10 \%$ impedance) and 25 (eg. fully loaded 400kVA transformer with $4 \%$ impedance) which covers most of practical systems is considered. These show the variations established using (12) and three-power load flow analysis.

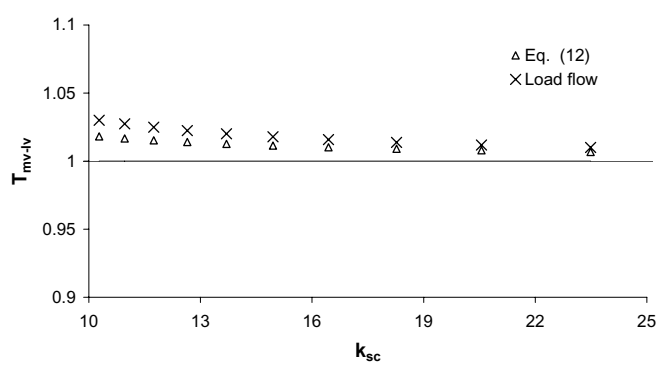

Fig. 3. Variation of $T_{m v-l v}$ with $k_{s c}$ in relation to constant current loads with 0.99 lagging power factor

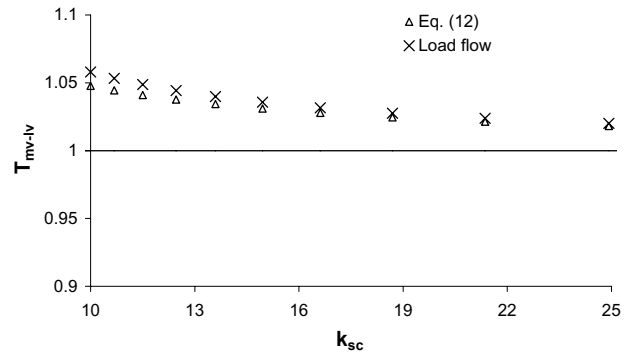

Fig. 4. Variation of $T_{m v-l v}$ with $k_{s c}$ in relation to constant current loads with 0.9 lagging power factor

\section{Constant Power LoAds}

As linearisation of system equations and simplifying assumptions (as in the case of constant current loads) are not supported by constant power loads, results obtained from three-phase load flow analysis were analysed and (13) was established considering operating scenarios most likely to occur in practice as a closer approximation to $\left|V_{-}^{l v}\right|$ :

$$
\left|V_{-}^{l v}\right| \approx \frac{\left|V_{-}^{m v}\right|}{\left|1+j \frac{1}{k_{s c}} \angle \theta_{p f}\right|^{\beta}}
$$

where,

$\beta \approx-1$ and -2 for low $(\sim 0.9)$ and high $(\sim 1)$ lagging power factor conditions respectively

Substituting (7) and (13) in (4):

$$
T_{m v-l v} \approx\left|1+j \frac{1}{k_{s c}} \angle \theta_{p f}\right|^{1-\beta}
$$

That is, the transfer coefficient $T_{m v-l v}$ increases by the factor $\left|1+j \frac{1}{k_{s c}} \angle \theta_{p f}\right|^{\beta-1}$ relative to the conservative value of unity when the system supplies constant power loads. Figs. 5 and 6 illustrate the variation of $T_{m v-l v}$ with $k_{s c}$ in relation to constant power loads with 0.99 and 0.9 power factor (lagging) respectively. These show the variations established using (14) and three-phase load flow analysis.

\section{INDUCTION MOTOR LOADS}

When the LV busbar supplies three-phase induction motors which can be represented using decoupled, unequal and constant (for a given motor speed) sequence impedances, (8) can be simplified as:

$$
\left|V_{-}^{l v}\right|=\frac{\left|V_{-}^{m v}\right|}{\left|1+\frac{Z_{++: t f}^{\prime}}{Z_{--i m}}\right|} \approx \frac{\left|V_{-}^{m v}\right|}{1+\frac{k_{s}}{k_{s c}}}
$$

where,

$Z_{--: i m}$ - negative sequence impedance of the aggregated induction motor load supplied by the LV busbar

Substituting (7) and (15) in (4):

$$
T_{m v-l v} \approx \frac{\left|1+j \frac{1}{k_{s c}} \angle \theta_{p f}\right|}{1+\frac{k_{s}}{k_{s c}}}
$$


The value of $k_{s}$ which is the ratio between positive and negative sequence impedances of an induction motor is usually around 5 to 7 . Hence, $1+\frac{k_{s}}{k_{s c}}>\left|1+j \frac{1}{k_{s c}} \angle \theta_{p f}\right|$ resulting $T_{m v-l v}<1$. Fig. 7 illustrates the variation of $T_{m v-l v}$ with $k_{s c}$ in relation to induction motor loads $\left(k_{s}=6.7\right.$, power factor $=0.9$, lagging). This shows the variations established using (16), (3) and three-phase load flow analysis. It is worthwhile noting that this reduction in $T_{m v-l v}$ relative to the value of unity (eg. $20 \%$ at $k_{s c}=25$ for the case considered in Fig. 7) is apparent compared to the increment in $T_{m v-l v}$ caused by passive loads (eg. $4 \%$ at $k_{s c}=25$ for the case considered in Fig. 6).

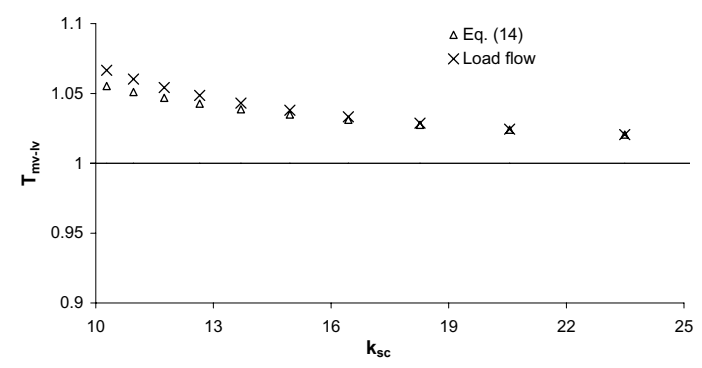

Fig. 5. Variation of $T_{m v-l v}$ with $k_{s c}$ in relation to constant power loads with 0.99 lagging power factor

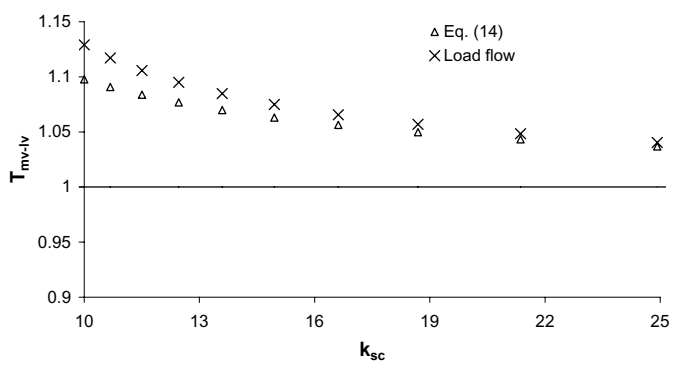

Fig. 6. Variation of $T_{m v-l v}$ with $k_{s c}$ in relation to constant power loads with 0.9 lagging power factor

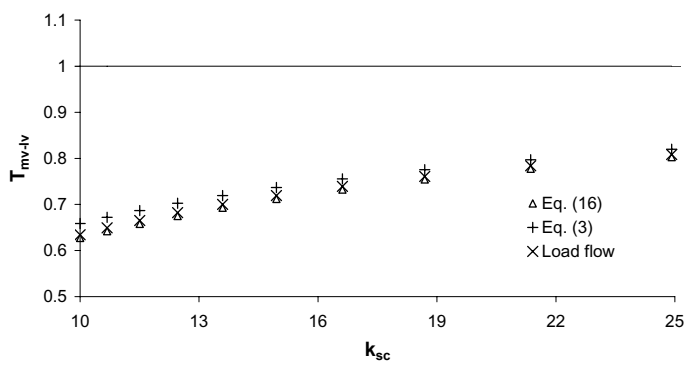

Fig. 7. Variation of $T_{m v-l v}$ with $k_{s c}$ in relation to induction motor loads

\section{Generalisation For a MiX of Various LoAd TYPES}

Consider a mix of parallel connected three-phase induction motors $(I M)$, constant impedance $(Z)$, constant current $(I)$ and constant power $(P Q)$ loads is supplied by the LV busbar. Then, the negative sequence current $I_{-: t f}$ in (8) can be decomposed as:

$$
I_{-: t f}=I_{-: i m}+I_{-: z}+I_{-: i}+I_{-: p q}
$$

where,

$I_{-: i m}, I_{-: z}, I_{-: i}, I_{-: p q}$ - negative sequence current (referred to the transformer primary) in $I M, Z, I$ and $P Q$ branches respectively arising as a result of the MV unbalance

Then, (8) can be expanded employing (17) as:

$$
\left|V_{-}^{l v}\right|=\left|V_{-}^{m v}-\sum_{L_{i}=i m, z, i, p q} Z_{++: t f} I_{-: L_{i}}\right|
$$

Appendix A describes that the impact of each $Z_{++: t f} I_{-: L_{i}}$ component in (18) where $L_{i}=i m, z, i, p q$ on the resultant voltage $\left|V_{-}^{l v}\right|$ can be replaced as:

$$
\left|V_{-}^{l v}\right| \approx \frac{\left|V_{-}^{m v}\right|}{\left(1+\frac{k_{m} k_{s}}{k_{s c}}\right)\left|1+j \frac{k_{z}}{k_{s c}} \angle \theta_{p f: z}\right|\left|1+j \frac{k_{p q}}{k_{s c}} \angle \theta_{p f: p q}\right|^{\beta}}
$$

where,

$k_{m}, k_{z}, k_{p q}$ - ratio of the induction motor load (in MVA), constant impedance and constant power loads (in MVA) to the total load (in MVA) supplied by the LV busbar respectively $\theta_{p f: z}, \theta_{p f: p q}$ - power factor angle of the constant impedance and constant power loads respectively

Substituting (7) and (19) in (4), the transfer coefficient $T_{m v-l v}$ can be expressed in a generalised form as:

$T_{m v-l v} \approx \frac{\left|1+j \frac{1}{k_{s c}} \angle \theta_{p f}\right|}{\left(1+\frac{k_{m} k_{s}}{k_{s c}}\right)\left|1+j \frac{k_{z}}{k_{s c}} \angle \theta_{p f: z}\right|\left|1+j \frac{k_{p q}}{k_{s c}} \angle \theta_{p f: p q}\right|^{\beta}}$

Figs. 8 and 9 illustrate the variation of $T_{m v-l v}$ with $k_{s c}$ in relation to two load bases: (a) Z-10\%, I-5\%, PQ-15\%, IM-70\% $\left(k_{s}=6.7\right)$ and (b) Z-25\%, I-5\%, PQ-60\%, IM-10\% ( $\left.k_{s}=6.7\right)$ respectively. A lagging power factor of 0.9 is assumed for all load components. These show the variations established using (20), (3) and three-phase load flow analysis. These results indicate that although the expression given by (3) is accurate in relation to a load base containing a large proportion of induction motors, the associated error is considerable for a load base dominated by passive elements. Further, Figs. 8 and 9 justify (20) as an improved expression for estimating the transfer coefficient $T_{m v-l v}$.

Figs. 10 (a) and (b) illustrate the variation of $T_{m v-l v}$ (derived using (20)) with $k_{m}=1-k_{p q}$ (related to load bases containing $I M$ and $P Q$ ) and $k_{m}=1-k_{z}$ (related to load bases containing $I M$ and $Z$ ) respectively, demonstrating the ranges in which the transfer coefficient $T_{m v-l v}$ can vary depending on system and load characteristics. The two cases where $k_{s c} \approx 25$ (representing the maximum) and $k_{s c} \approx 10$ (representing the minimum), a lagging power factor of 0.9 for all load components and $k_{s}=6.7$ for induction motors are 


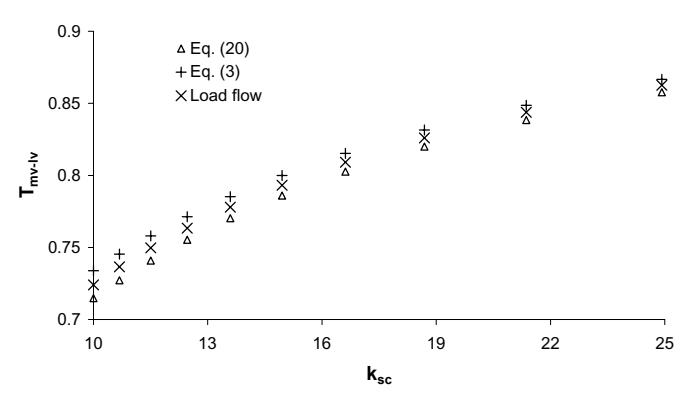

Fig. 8. Variation of $T_{m v-l v}$ with $k_{s c}$ in relation to a load base with Z-10\%, $\mathrm{I}-5 \%, \mathrm{PQ}-15 \%$ and IM-70\%

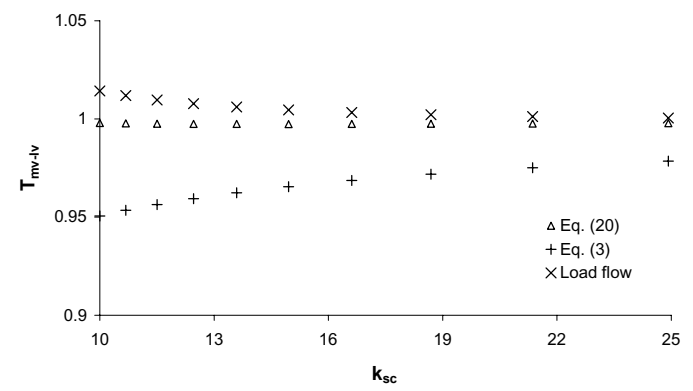

Fig. 9. Variation of $T_{m v-l v}$ with $k_{s c}$ in relation to a load base with Z-25\%, $\mathrm{I}-5 \%, \mathrm{PQ}-60 \%$ and IM-10\%

considered. These indicate that the transfer coefficient $T_{m v-l v}$ can typically vary in a range: $1.1<T_{m v-l v}<0.6$.

The generalised transfer coefficient $T_{m v-l v}$ given by (20) can be simplified in relation to an industrial load base containing a large proportion $(>50 \%)$ of induction motors by neglecting the negative sequence currents $I_{-: z}, I_{-: i}$, and $I_{-: p q}$ compared to $I_{-: i m}$ in (17) as:

$$
T_{m v-l v} \approx \frac{\left|1+j \frac{1}{k_{s c}} \angle \theta_{p f}\right|}{1+\frac{k_{m} k_{s}}{k_{s c}}}
$$

Fig. 11 illustrates the variation of $T_{m v-l v}$ with $k_{m}$ established using three-phase load flow analysis, (20), (21) and (3). The load bases consisting constant power loads (power factor $=0.9$, lagging) and induction motors $\left(k_{s}=6.7\right.$, power factor $=0.9$, lagging), and the case where $k_{s c} \approx 10$ are considered.
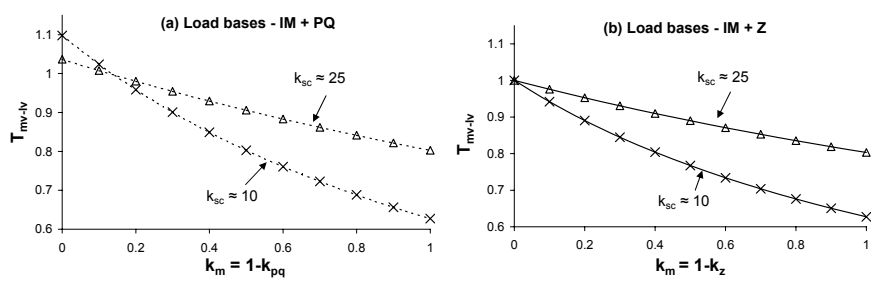

Fig. 10. Variation of $T_{m v-l v}$ (a) with $k_{m}=1-k_{p q}$ (b) with $k_{m}=1-k_{z}$, for the two cases where $k_{s c} \approx 25$ and $k_{s c} \approx 10$

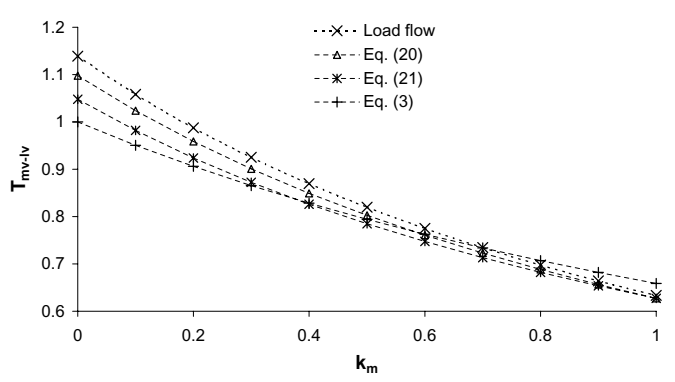

Fig. 11. Variation of $T_{m v-l v}$ with $k_{m}$ obtained from three-phase load flow analysis (LF), (20), (21) and (3) in relation to the case where $k_{s c} \approx 10$

\section{CONCLUSIONS}

The paper has addressed the propagation of voltage unbalance from MV to LV systems which is an important aspect in determining the voltage unbalance emission limits to unbalanced installations supplied by LV systems based on the guidelines given in IEC/TR 61000-3-13. The behaviour of various load types has been addressed and the outcomes were employed to develop a generalised and improved methodology for estimating the MV to LV transfer coefficient precisely. Following major conclusions can be drawn from the study:

(a) The MV to LV voltage unbalance transfer coefficient increases by the factors $\left|1+j \frac{1}{k_{s c}} \angle \theta_{p f}\right|$ and $\left|1+j \frac{1}{k_{s c}} \angle \theta_{p f}\right|^{\beta-1}$ relative to the conservative value of unity when the LV system supplies constant current and constant power loads respectively.

(b) The MV voltage unbalance attenuates as it propagates to downstream LV system by the factor $\frac{\left|1+j \frac{1}{k_{s c}}<\theta_{p f}\right|}{1+\frac{k_{s}}{k_{s c}}}$ when the LV system supplies three-phase induction motors.

(c) The transfer coefficient $T_{m v-l v}$ can typically vary in a range: $1.1<T_{M V-L V}<0.6$ depending on system and load characteristics.

\section{APPENDIX A}

Consider a series of constant impedance loads $L_{1}, L_{2}, \ldots$, $L_{i}, \ldots, L_{n}$ (balanced: equal positive and negative sequence impedances) is supplied by the LV busbar. Referring to (8), it can be simplified as:

$$
\begin{aligned}
V_{-}^{l v} & =\frac{V_{-}^{m v}}{1+Z_{++: t f}^{\prime}\left(\frac{1}{Z_{++: L_{1}}}+\frac{1}{Z_{++: L_{2}}}+\ldots+\frac{1}{Z_{++: L_{n}}}\right)} \\
& =\frac{V_{-}^{m v}}{1+j \frac{k_{L_{1}}}{k_{s c}} \angle \theta_{p f: L_{1}}+j \frac{k_{L_{2}}}{k_{s c}} \angle \theta_{p f: L_{2}}+\ldots+j \frac{k_{L_{n}}}{k_{s c}} \angle \theta_{p f: L_{n}}}
\end{aligned}
$$

where,

$Z_{++: L_{i}}$ - positive sequence impedance of load $L_{i}$

$k_{L_{i}}$ - ratio between load $L_{i}$ (in MVA) and the total load (in MVA) supplied by the LV busbar

$\theta_{p f: L_{i}}$ - power factor angle of load $L_{i}$

Equation (A.1) can be rearranged into the form given by (A.2) by neglecting $\frac{k_{L_{i}} k_{L_{j}}}{k_{s c}^{2}}$ and higher order terms, as $\frac{k_{L_{i}} k_{L_{j}}}{k_{s c}^{2}} \ll 1$ and $\frac{k_{L_{i}}}{k_{s c}}$. 


$$
V_{-}^{l v} \approx \frac{V_{-}^{m v}}{\left(1+j \frac{k_{L_{1}}}{k_{s c}} \angle \theta_{p f: L_{1}}\right)\left(1+j \frac{k_{L_{2}}}{k_{s c}} \angle \theta_{p f: L_{2}}\right) \ldots\left(1+j \frac{k_{L_{n}}}{k_{s c}} \angle \theta_{p f: L_{n}}\right)}
$$

Alternatively, the negative sequence voltage $V_{-}^{l v}$ in (8) can be expressed by decomposing the negative sequence current $I_{-: t f}$ (ie. $I_{-: t f}=I_{-: L_{1}}+I_{-: L_{2}}+\ldots+I_{-: L_{n}}$ ) as:

$$
V_{-}^{l v}=V_{-}^{m v}-\sum_{i=1}^{n} Z_{++: t f} I_{-: L_{i}}
$$

where,

$I_{-: L_{i}}$ - negative sequence current (referred to the transformer primary) in load $L_{i}$ arising as a result of the MV unbalance

Comparing (A.2) and (A.3) it can be seen that the impact of each $Z_{++: t f} I_{-: L_{1}}$ component in (A.3) on the resultant voltage $\left|V_{-}^{l v}\right|$ has been replaced by the factor $\left|\frac{1}{1+j \frac{k_{L_{i}}}{k_{s c}} \angle \theta_{p f: L_{i}}}\right|$ (say, replacement factor) in (A.2).

Consider a case where the LV busbar supplies $L_{i}, L_{j}$, $L_{k}$ and $L_{l}$ representing induction motors $(I M)$, constant impedance $(Z)$, constant current $(I)$ and constant power $(P Q)$ loads respectively. According to the above observation, the impact of the corresponding components $Z_{++: t f} I_{-: i m}$, $Z_{++: t f} I_{-: z}, Z_{++: t f} I_{-: i}$ and $Z_{++: t f} I_{-: p q}$ on the resultant voltage $\left|V_{-}^{l v}\right|$ can be considered independently and replaced similar to (A.2). However, as seen in Sections III - VI (see (9), (11), (13) and (15)) the components $Z_{++: t f} I_{-: i m}, Z_{++: t f} I_{-: z}$, $Z_{++: t f} I_{-: i}$ and $Z_{++: t f} I_{-: p q}$ exhibit different behaviour on $\left|V_{-}^{l v}\right|$ which are to be accommodated in the corresponding replacement factors as given in Table A.1.

TABLE A.1

REPLACEMENT FACTORS CORRESPONDING TO VARIOUS LOAD TYPES

\begin{tabular}{c|c} 
Load type & Replacement factor \\
\hline IM & $\frac{1}{\left(1+\frac{k_{s} k_{m}}{k_{s c}}\right)}$ \\
Z & $\frac{1}{\left|1+j \frac{k_{z}}{k_{s c}} \angle \theta_{p f: z}\right|}$ \\
I & $\frac{1}{\text { PQ }}$ \\
\hline $1+\left.j \frac{k_{p q}}{k_{s c}} \angle \theta_{p f: p q}\right|^{\beta}$
\end{tabular}

\section{REFERENCES}

[1] Joint Working Group CIGRE/CIRED C4.103 (formely Cigre C4.06), "Assesment of Emission Limits for the Connection of Disturbing Installtions to Power Systems", Final Report, June 2007.

[2] Robert Koch, Germain Beaulieu, Luc Berthet and Mark Halpin "Recommended Methods of Determining Power Qality Emission Limits for Installations Connected to EHV, HV, MV and LV power systems", 19th International Conferance on Electricity Distribution, paper 0893, Vienna, 21-24 May 2007.
[3] Robert Koch, Germain Beaulieu, Luc Berthet and Mark Halpin "International Survey of Unbalance Levels in LV, MV, HV and EHV Power Systems: CIGRE/CIRED JWG C4.103 Results", 19th International Conferance on Electricity Distribution, paper 0892, Vienna, 21-24 May 2007.

[4] "Electromagnetic Compatibility (EMC) - Limits - Assessment of Emission Limits for the Connection of Unbalanced Installations to MV, HV and EHV Power Systems", IEC Technical Report 61000-3-13, Ed. 1, 2008.

[5] "Electromagnetic Compatibility (EMC) - Limits - Assessment of Emission Limits for Distorting Loads in MV and HV Power Systems", IEC Technical Report 61000-3-6, Ed. 1, 1996.

[6] "Electromagnetic Compatibility (EMC) - Limits - Assessment of Emission Limits for Distorting Loads in MV and HV Power Systems", IEC Technical Report 61000-3-7, Ed. 1, 1996.

[7] Prabodha Paranavithana, Sarath Perera and Danny Sutanto, "Impact of Untransposed $66 \mathrm{kV}$ Sub-transmission Lines on Voltage Unbalance", Australasian Universities Power Engineering Conference, AUPEC, Paper 28, Melbourne-Australia, Dec. 2006.

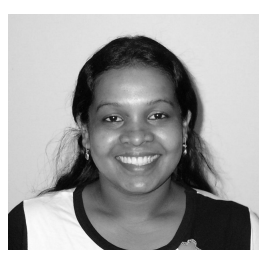

Prabodha Paranavithana received the B.Sc.(Eng) (Hons.) degree in electrical power engineering from the University of Moratuwa, Sri Lanka.

Currently she is pursuing studies towards the Ph.D. degree at the University of Wollongong, Australia. Her research interests are in power quality and power system analysis.

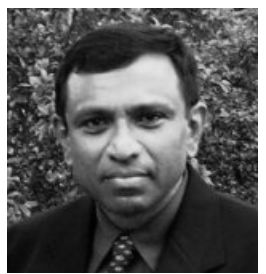

Sarath Perera received the B.Sc.(Eng) degree in electrical power engineering from the University of Moratuwa, Sri Lanka, a M.Eng.Sc. degree from the University of New South Wales, Australia, and the $\mathrm{Ph} . \mathrm{D}$. degree from the University of Wollongong, Australia.

$\mathrm{He}$ has been a lecturer at the University of Moratuwa, Sri Lanka. Currently he is an Associate Professor with the University of Wollongong. He is the Technical Director of the Integral Energy Power Quality and Reliability Centre at the University of

Wollongong.

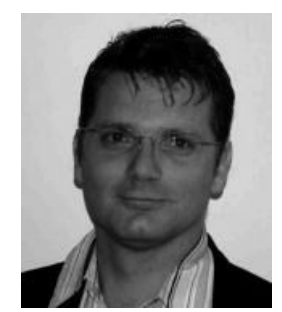

Robert Koch received the B.Eng. and M.Eng. degrees in electrical power engineering from the University of Stellenbosch, South Africa.

$\mathrm{He}$ is a Corporate Specialist with Eskom Holdings Limited, South Africa and Convener of IEC 77A/WG8 - the working group responsible for publishing IEC/TR 61000-3-13. He is an active participant in Cigre working groups - and was the document coordinator for the Cigre report on which IEC 61000-3-13 was based. He is currently the Convener of Advisory Group C4.1 (Power Qualiy), of Study Committee C4 (System Technical Performance). 